\title{
Viabilidade financeira de arranjos agroflorestais biodiversos: estudo de casos no Mato Grosso do Sul, Brasil
}

Financial feasibility of biodiverse agroforestry arrangements: case study in Mato Grosso do Sul, Brazil

Viabilidad financiera de los arreglos agroforestales biodiversos: estudo de casos en el Mato Grosso do Sul, Brasil

Landi Aramí Rossato Paulus ORCID: https://orcid.org/0000-0002-1123-6831 Universidade Federal da Grande Dourados, Brasil E-mail: landirossato@gmail.com

Zefa Valdivina Pereira

ORCID: https://orcid.org/0000-0001-5328-2169 Universidade Federal da Grande Dourados, Brasil E-mail: zefapereira@ufgd.edu.br

Marcelo Francia Arco-Verde ORCID: https://orcid.org/0000-0001-6545-9961 Embrapa Florestas, Colombo, Brasil

E-mail: marcelo.arco-verde@embrapa.br

Jósimo Diego Bazanella Linê

ORCID: https://orcid.org/0000-0002-5914-5656 Universidade Federal da Grande Dourados, Brasil E-mail: josimo_line@hotmail.com

Milton Parron Padovan ORCID: https://orcid.org/0000-0002-7888-1915 Empresa Brasileira de Pesquisa Agropecuária Oeste, Brasil E-mail: milton.padovan@embrapa.br

Marcelo Adriano Rodrigues do Santos

ORCID: https://orcid.org/0000-0002-2080-452X Escola Estadual Reynaldo Massi, Brasil

E-mail: professormarcelo10@yahoo.com.br

\begin{abstract}
Resumo
Visando fornecer subsídio para o planejamento de sistemas agroflorestais (SAFs) biodiversos, este trabalho apresenta a análise da viabilidade financeira de quatro diferentes modelos agroflorestais, no campo experimental da Escola Municipal Rural Benedita Figueiró, Município de Ivinhema - MS. Os arranjos de SAFs analisados são compostos por 45 espécies florestais e 9 espécies com fim comercial: Sistema Café + Banana, Sistema Café com Floresta, Sistema Abacaxi e Sistema Cumari. Após o levantamento dos custos de implantação, manutenção e receitas previstas, foi feita a análise financeira para o período de 20 anos, utilizando a planilha AmazonSAF. Três modelos apresentaram saldo líquido final positivo, mas com desempenho insatisfatório na fase de estabilidade. O consórcio de espécies arbóreas com café e banana demonstrou ser viável para recuperação com retorno financeiro. O café favorece o fluxo de caixa de longo prazo do projeto. O menor tempo para retorno de investimento foi obtido no Sistema Abacaxi, graças à receita das culturas de ciclo curto. $\mathrm{O}$ espaçamento adotado gerou excesso de sombreamento, indicando a necessidade de desbaste seletivo, no $6^{\circ}$ ano, de indivíduos arbóreos que estejam retirando a incidência solar sobre as linhas das cultiváveis. Na fase de planejamento do sistema, sugere-se a inserção de culturas anuais às entrelinhas do SAF Café + Banana, para melhorar o período de recuperação do valor investido. As pesquisas devem ser exploradas no sentido de estabelecer diretrizes para composição de modelos agroflorestais biodiversos, que possam servir como referência para que agricultores encontrem segurança nesta modalidade de produção.
\end{abstract}

Palavras-chave: Sistema agroflorestal; Indicadores financeiros; Sustentabilidade; Biodiversidade.

\section{Abstract}

Aiming to provide aid for planning biodiverse Agroforestry Systems (AF), this paper presents an analysis of the financial viability of four different agroforestry models, in the experimental field of Escola Municipal Rural Benedita Figueiró, Ivinhema - MS county. The analyzed AF arrangements are composed of 45 forest species and 9 species for commercial purposes: Coffee + Banana System, Coffee with Forest System, Pineapple System and Cumari System. 
After surveying the costs of implementation, maintenance and expected revenues, a financial analysis was made for the period of 20 years, using AmazonSAF spreadsheet. Three models presented final positive net balance, but underperforming in the stability phase. The consortium of Forest Species with Coffee and Banana proved to be viable for recovery with financial return. Coffee favors the peoject's long-term cash flow. The shortest time to return on investment was obtained in the Pineapple System, as it represents a short cycle culture. The adopted spacing generated an shading excess, indicating the need of selective trimming, int the 6th year, of arboreal individuals who are removing the solar incidence on the cultivable lines. In the system planning phase, it is suggested to insert annual crops between the lines of AF Coffee + Banana, to reduce the period of return on investment. Research should be explored in order to establish guidelines for the composition of biodiverse agroforestry models, which can serve as a reference for farmers to find security in this type of production.

Keywords: Agroforestry systems; Financial indicators; Sustainability; Biodiversity.

\section{Resumen}

Con el objetivo de brindar subsidio para la planificación de sistemas agroforestales biodiversos (SAFs), este trabajo presenta el análisis de la viabilidad financiera de cuatro modelos agroforestales diferentes, en el campo experimental de la Escola Municipal Rural Benedita Figueiró, Municipio de Ivinhema - MS. Los arreglos de SAFs analizados están compuestos por 45 especies forestales y 9 especies con fines comerciales: Sistema Café + Banano, Sistema Café con Bosque, Sistema Ananá y Sistema Ají Habanero (Cumari). Luego de relevar los costos de implementación, mantenimiento e ingresos esperados, se realizó un análisis financiero para el período de 20 años, utilizando la hoja de cálculo de AmazonSAF. Tres modelos presentaron saldo final neto positivo, pero con un desempeño insatisfactorio en la fase de estabilidad. La combinación de especies arbóreas con café y banano demostró ser viable para la recuperación con rentabilidad financiera. El café favorece el flujo de caja de largo plazo del proyecto. El menor tiempo de retorno de la inversión se obtuvo en el Sistema Ananá, gracias a los ingresos de los cultivos de ciclo corto. El espaciamiento adoptado generó un sombreado excesivo, lo que indica la necesidad de un raleo selectivo, en el sexto año, de los individuos arbóreos que están eliminando la incidencia solar en las líneas cultivables. En la fase de planificación del sistema, se sugiere la inserción de cultivos anuales entre las líneas de SAF Café + Banano, para mejorar el período de recuperación del monto invertido. Se debe explorar la investigación con el fin de establecer pautas para la composición de modelos agroforestales biodiversos, que puedan servir de referencia para que los agricultores encuentren seguridad en este tipo de producción.

Palabras clave: Sistema agroforestal; Indicadores financieros; Sostenibilidad; Biodiversidad.

\section{Introdução}

A exploração dos recursos naturais de forma insustentável tem despertado a consciência ambiental da sociedade e dos cientistas, os quais estão em busca do equilíbrio entre produção de alimentos e conservação da biodiversidade (Silva e Silva, 2020). Para atingir este objetivo, sistemas agroflorestais são citados como uma excelente alternativa em encontros da comunidade científica (Camargo et al., 2019; Padovan et al., 2019; Garcia et al., 2020).

Ressalta-se que sistemas agroflorestais (SAFs) são sistemas de produção de bens e/ou serviços que, adotando práticas de manejo sustentável da terra, incrementam a produção, ao integrar cultivos agrícolas anuais ou perenes com o componente florestal e/ou animais, com dependência mínima de insumos externos, concretizando-os como uma relevante estratégia para recuperar áreas degradadas e áreas de reserva legal, além de serem compatíveis com os padrões culturais das populações locais (Balbino et al., 2011; Jose, 2012; Silva, 2013; Udawatta et al., 2019; Garcia et al., 2020).

A utilização de Sistemas Agroflorestais tem sido, nas últimas décadas, bastante difundida como alternativa para a restauração ecológica, atribuindo-se à combinação de espécies arbóreas com culturas agrícolas e/ou animais a melhoria nas propriedades físico-químicas de solos degradados, bem como na atividade de microrganismos, considerando a possibilidade de um grande número de fontes de matéria orgânica (Miccolis et al., 2016; Zomer et al., 2016; Coelho, 2017). Os SAFs constituem importante alternativa, pois apresentam grande potencial para a produção de diversificados serviços ambientais, produção de alimentos e geração de renda aos produtores rurais (Udawatta et al., 2019; Padovan et al. 2019).

Um grande desafio, exposto por Silva (2013) nas pesquisas agroflorestais, é planejar um SAF de maneira que haja um equilíbrio entre a biodiversidade, a complexidade e a rentabilidade. Amaral-Silva et al. (2015) apontam a necessidade de estudos acerca da viabilidade financeira em SAFs biodiversos, que possam basear políticas públicas para a adoção de práticas agrícolas sustentáveis. Visando facilitar esta tarefa, Arco-Verde e Amaro (2010) desenvolveram uma ferramenta para avaliação 
financeira destes sistemas - AmazonSAF -, através da qual é possível verificar se o sistema de produção gerará retorno do capital investido, auxiliando os produtores na tomada de decisão (Arco-Verde \& Amaro, 2015).

Inseridos nesse contexto, este trabalho objetivou avaliar a viabilidade financeira de quatro arranjos agroflorestais biodiversos no município de Ivinhema, MS.

\section{Metodologia}

\section{Descrição dos Arranjos Agroflorestais}

Este trabalho foi desenvolvido no campo experimental da Escola Municipal Rural Benedita Figueiró de Oliveira, nas coordenadas $22^{\circ} 18^{\prime} 50^{\prime \prime} \mathrm{S}$ e $53^{\circ} 49^{\prime} 3^{\prime \prime} \mathrm{W}$, no Município de Ivinhema - MS, Brasil.

A área encontra-se em Latossolo Vermelho Distrófico (LVAd), a uma altitude de $420 \mathrm{~m}$, e pertence à Bacia Hidrográfica do Rio Ivinhema. (Motta, 2011). O clima da região é tropical com estação seca (classificação climática de Köppen-Geiger: Aw) (Köppen \& Geiger, 1928). De acordo com Souza (2010), a pluviosidade anual oscila entre $1500 \mathrm{~mm}$ e 1700 mm. A vegetação é classificada como Floresta Estacional Semidecidual - Bioma Atlântico (IBGE, 2012).

O SAF estudado apresenta uma área de $10.272 \mathrm{~m}^{2}$, formado por quatro diferentes arranjos, dispostos em aleias. O espaçamento adotado foi de 2,5 metros entre linhas, as bananeiras com 3 metros entre plantas, e 3 metros entre arbóreas lenhosas. Os indivíduos dos cultivos adensados encontram-se dispostos nas linhas de forma irregular, não ocupando toda a área disponível, porém, de uma forma geral, o espaçamento adotado para mamão, mandioca e pimenta foi de 1 metro entre plantas e, nas fileiras simples de abacaxi entre linhas, há 0,80 m entre plantas. As espécies Crotalaria spectabilis Röth, Stylosanthes sp e Canavalia ensiformis (L.) DC foram implantadas nas entrelinhas das culturas de interesse econômico para fins de adubação verde. As espécies arbóreas presentes em cada SAF estão descritas na tabela 2.

$\mathrm{Na}$ Tabela 1 encontram-se as espécies de interesse comercial, espaçamento e densidade que compõem cada arranjo agroflorestal biodiverso e, na Figura 1, encontra-se o croqui de cada arranjo. 


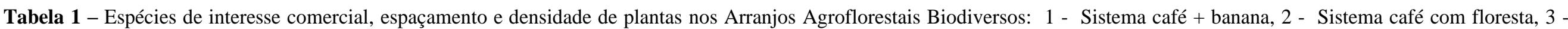
Sistema Abacaxi e 4 - Sistema Cumari, em Ivinhema, MS, 2016.

\begin{tabular}{|c|c|c|c|c|c|c|c|c|c|c|c|c|c|}
\hline \multirow{3}{*}{ Nome Vulgar } & \multirow{3}{*}{ Nome Científico } & \multicolumn{3}{|c|}{$\begin{array}{c}\text { SAF 1 } \\
\text { Sistema café + banana } \\
\end{array}$} & \multicolumn{3}{|c|}{$\begin{array}{c}\text { SAF } 2 \\
\text { Sistema café + floresta } \\
\end{array}$} & \multicolumn{3}{|c|}{$\begin{array}{c}\text { SAF 3 } \\
\text { Sistema Abacaxi } \\
\end{array}$} & \multicolumn{3}{|c|}{$\begin{array}{c}\text { SAF4 } \\
\text { Sistema Cumari } \\
\end{array}$} \\
\hline & & \multirow{2}{*}{$\begin{array}{c}\text { Esp. } \\
\text { (metros) }\end{array}$} & \multicolumn{2}{|c|}{ Densidade } & \multirow{2}{*}{$\begin{array}{c}\text { Esp. } \\
\text { (metros) }\end{array}$} & \multicolumn{2}{|c|}{ Densidade } & \multirow{2}{*}{$\begin{array}{c}\text { Esp. } \\
\text { (metros) }\end{array}$} & \multicolumn{2}{|c|}{ Densidade } & \multirow{2}{*}{ Esp. (metros) } & \multicolumn{2}{|c|}{ Densidade } \\
\hline & & & $3676 \mathrm{~m}^{2}$ & 1 ha & & $3676 \mathrm{~m}^{2}$ & 1 ha & & $3676 \mathrm{~m}^{2}$ & 1 ha & & $3676 \mathrm{~m}^{2}$ & 1 ha \\
\hline Abacaxi & Ananas comosus L. Merril & - & - & - & - & - & - & $\begin{array}{c}0,8 \times 2,5 \\
\text { (entrelinhas }\end{array}$ & s) $\quad 854$ & 6466 & - & - & - \\
\hline Lichia & Litchi chinensis Sonn & $3 \times 10$ & 1 & 2 & $3 \times 5$ & 1 & 3 & - & - & - & $3 \times 2,5$ & 1 & 7 \\
\hline $\begin{array}{l}\text { Aroeira } \\
\text { Pimenteira }\end{array}$ & Schinus terebinthifolius Raddi & $3 \times 10$ & 11 & 27 & $3 \times 5$ & 3 & 7 & $3 \times 2,5$ & 3 & 23 & $3 \times 2,5$ & 2 & 14 \\
\hline Jenipapo & Genipa americana $\mathrm{L}$. & $3 \times 10$ & 9 & 22 & $3 \times 5$ & 5 & 11 & $3 \times 2,5$ & 2 & 14 & - & - & - \\
\hline $\begin{array}{l}\text { Banana } \\
\text { Nanicão }\end{array}$ & Musa paradisíaca $\mathrm{L}$. & $3 \times 10$ & 104 & 321 & $3 \times 10$ & 60 & 180 & $3 \times 12,5$ & 17 & 136 & $3 \times 10$ & 17 & 119 \\
\hline Café & Coffea arabica L. IAPAR 59 & $1 \times 5$ & 473 & 1.413 & $1 \times 5$ & 405 & 1215 & - & - & - & - & - & - \\
\hline Mandioca & Manihot esculenta Crantz & - & - & - & - & - & - & $1 \times 2,5$ & 157 & 1221 & $1 \times 2,5$ & 89 & 623 \\
\hline Mamão & Carica papaia $\mathrm{L}$. & - & - & - & - & - & - & $1 \times 12,5$ & 16 & 128 & $\begin{array}{c}1 \times 10 \\
\text { (entrelinhas) }\end{array}$ & 84 & 588 \\
\hline Pimenta & & - & - & - & - & - & - & & & & & & \\
\hline $\begin{array}{l}\text { Cumari } \\
\text { verdadeira }\end{array}$ & Capsicum baccatum $\mathrm{L}$. & & & & & & & $1 \times 12$ & 54 & 432 & $1 \times 2,5$ & 92 & 644 \\
\hline $\begin{array}{l}\text { Espécies } \\
\text { arbóreas } \\
\text { (conservação } \\
\text { da } \\
\text { biodiversidade) } \\
*\end{array}$ & Componente florestal & $3 \times 10$ & 128 & 298 & $3 \times 5$ & 158 & 405 & $3 \times 2,5$ & 88 & 675 & $3 \times 2,5$ & 58 & 406 \\
\hline
\end{tabular}

*Arranjo 1 - 31 espécies arbóreas; Arranjo 2 - 22 espécies arbóreas; Arranjo 3 - 25 espécies arbóreas; Arranjo 4 - 18 espécies arbóreas (lista de espécies na tabela 2). 
Figura 1 - Croquis dos Arranjos Agroflorestais Biodiversos: SAF1 - Sistema café + banana, SAF 2- Sistema café com floresta, SAF 3- Sistema Abacaxi e SAF 4 - Sistema Cumari, em Ivinhema, MS, 2016.

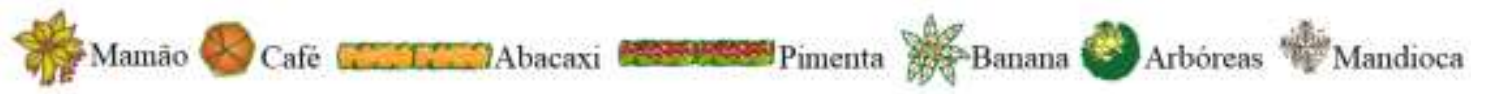

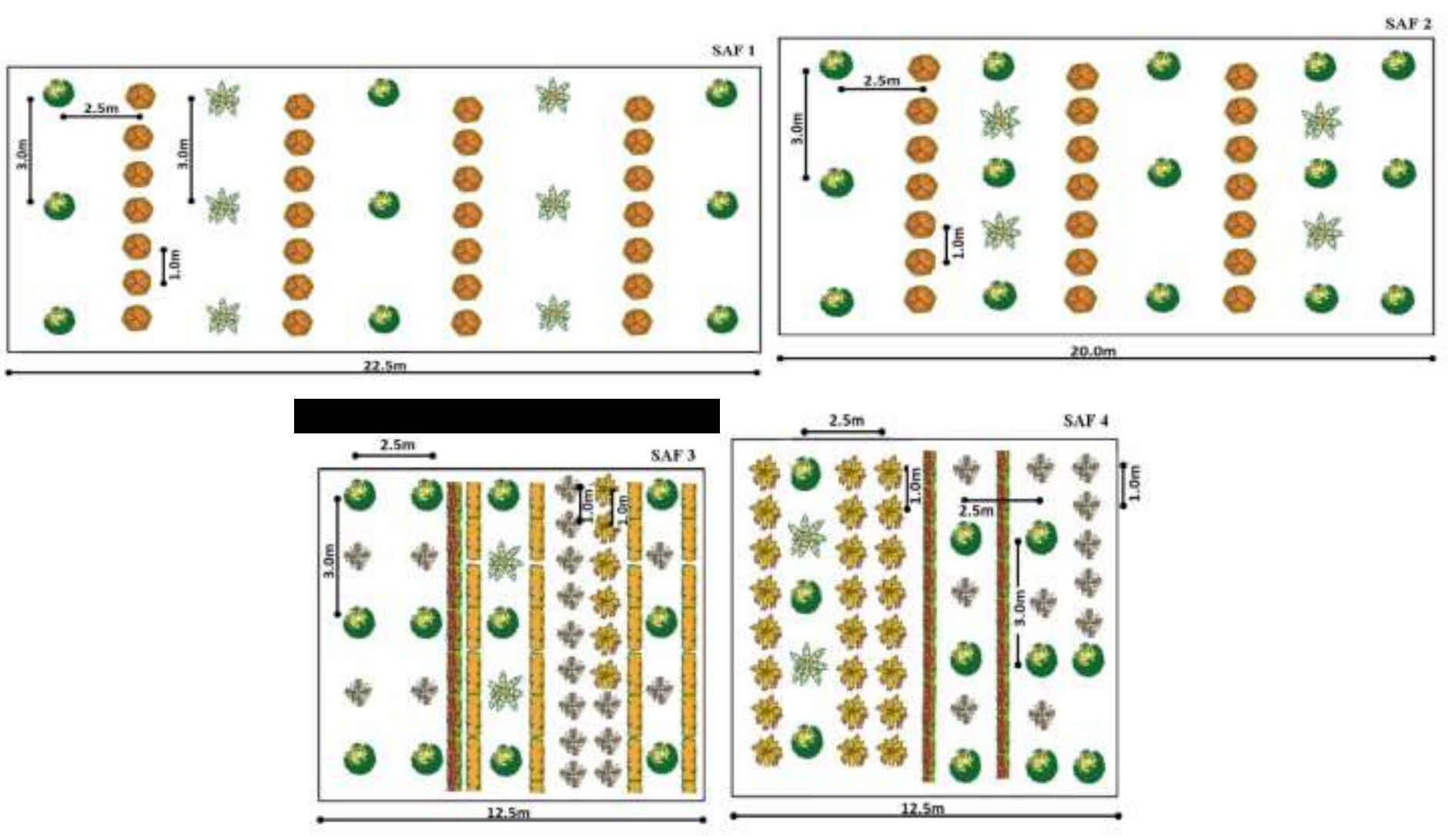

Fonte: Autores. 
Tabela 2 - Lista de espécies florestais e número de indivíduos presentes em cada Arranjo Agroflorestal em Ivinhema, MS, 2016.

\begin{tabular}{|c|c|c|c|c|c|c|}
\hline Família & Nome Científico & Nome Popular & SAF1 & SAF2 & SAF3 & SAF4 \\
\hline Anacardiaceae & Myracrodruon urundeuva Allemão & Aroeira & 5 & 5 & 9 & 5 \\
\hline Anacardiaceae & Spondias purpurea $\mathrm{L}$. & Siriguela & 1 & - & - & - \\
\hline Anacardiaceae & Spondias tuberosa Arruda & Umbu & 1 & - & - & - \\
\hline Anacardiaceae & Tapirira guianensis Aubl. & Peito de Pomba & 1 & 3 & - & - \\
\hline Annonaceae & Annona muricata $\mathrm{L}$ & Graviola & 2 & - & - & - \\
\hline Asteraceae & Gochnatia polimorfa (Less.) Cabrera & Candeia & 2 & 1 & 2 & 1 \\
\hline Bignoniaceae & Handroanthus sp & Ipê & 10 & - & 7 & - \\
\hline Bignoniaceae & Jacaranda $\mathrm{sp}$ & Jacarandá & 2 & - & 1 & - \\
\hline Bignoniaceae & Tabebuia roseoalba (Ridl.) Sandwith & Ipê Branco & & - & - & 2 \\
\hline Boraginaceae & Cordia americana (L.) Gottschiling \& J. S. Mill. & Guajuvira & 14 & - & 5 & - \\
\hline Caricaceae & Jacaratia spinosa (Aubl.) A.DC. & Jaracatiá & 7 & & - & - \\
\hline Fabaceae & Albizia niopoides (Spruce ex Benth.) Burkart & Farinha Seca & 7 & 5 & 2 & 1 \\
\hline Fabaceae & Amburana cearenses (Allemão) A. C. Sm. & Amburana & 1 & 1 & - & - \\
\hline Fabaceae & Anadenanthera colubrina (Vell.) Brenan & Angico & 2 & 1 & 1 & 5 \\
\hline Fabaceae & Bauhinia forficata Link & Pata de Vaca & - & 2 & 1 & - \\
\hline Fabaceae & Clitoria sp & Clitória & 2 & 3 & 1 & - \\
\hline Fabaceae & Cratylia bahiensis L. P. Queiroz & Cratília & 9 & - & - & - \\
\hline Fabaceae & Enterolobium contortisiliquum (Vell.) Morong & Tamboril & 6 & 2 & 2 & - \\
\hline Fabaceae & Hymenaea courbaril $\mathrm{L}$. & Jatobá & 5 & - & 2 & 2 \\
\hline Fabaceae & Inga vera Willd. e Inga laurina (Sw.) Willd & Ingá & 16 & - & 7 & 6 \\
\hline Fabaceae & Ormosia arborea (Vell.) Harms & Olho de Cabra & 1 & 2 & 3 & - \\
\hline Fabaceae & Peltophorum dubium (Spreng.) Taub. & Canafístula & 4 & 9 & 2 & 5 \\
\hline Fabaceae & Senegalia langsdorffii (Benth.) Seigler \& Ebinger & Monjoleiro & 4 & 5 & 2 & 4 \\
\hline Lecythidaceae & Cariniana legalis (Mart.) Kuntze & Jequitibá & 2 & - & 3 & - \\
\hline Malvaceae & Ceiba speciosa (A.St.-Hil.) Ravenna & Paineira & 2 & 7 & - & 1 \\
\hline Malvaceae & Guazuma ulmifolia Lam. & Mutambo & - & 6 & 10 & 8 \\
\hline Malvaceae & Luehea grandiflora Mart. \& Zucc. & Açoita Cavalo & - & 1 & 1 & 4 \\
\hline Meliaceae & Cedrela Fissilis Vell. & Cedro & 4 & 6 & 7 & 3 \\
\hline Moraceae & Ficus adhatifolia Schott in Spreng. & Figueira & 1 & - & 5 & 4 \\
\hline Moraceae & Maclura tinctoria (L.) D. Don ex Steud. & Amora Brava & 1 & 2 & 1 & 3 \\
\hline Myrsinaceae & Myrsine umbellata Mart. & Capororoca & - & 2 & - & \\
\hline Myrtaceae & Eugenia uniflora $\mathrm{L}$. & Pitanga & 4 & 9 & 4 & - \\
\hline Polygonaceae & Ruprechtia laxiflora Meisn. & Marmeleiro & 8 & 6 & 3 & 2 \\
\hline Polygonaceae & Triplaris americana $\mathrm{L}$ & Pau Formiga & 3 & 9 & 3 & 3 \\
\hline Sapindaceae & Alophyllus edulis (A.St.-Hil. Et al.) Hieron. Ex Niederl. & Cancum & 1 & - & - & - \\
\hline Sapindaceae & Magonia pubescens A.St.-Hil. & Timbó & 1 & 14 & 3 & 4 \\
\hline
\end{tabular}




\section{Método de análise}

Para análise dos dados utilizou-se a Planilha Eletrônica de Avaliação Financeira de Sistemas Agroflorestais AmazonSAF v 4-2,5 desenvolvida por Arco-Verde e Amaro (2010), que possibilita a entrada de dados referentes às espécies utilizadas, à produtividade e à especificação dos coeficientes técnicos.

Foram inventariados todos os componentes agroflorestais das espécies arbóreas e de todas as cultivares. Foi gerado um croqui, obtendo-se a área ocupada pelos diferentes arranjos agroflorestais. Após inserir as espécies e o espaçamento, foram calculadas as áreas.

A densidade dos componentes foi calculada a partir da projeção do desenho inicial e área que cada um dos arranjos de SAF ocupa, projetando-a para o tamanho da área avaliada - um hectare - para que houvesse exatidão ao alcançar os $10.000 \mathrm{~m}^{2}$, dispondo as linhas lateralmente, de forma contínua e horizontal. Respeitou-se o arranjo adotado, o espaçamento entre linhas e o número de indivíduos em cada linha.

Foi adotada metodologia qualiquantitativa, com o método de análise 'fotográfico', caracterizado como uma avaliação estática, baseada nas informações e coeficientes técnicos somente do período avaliado. A partir do acompanhamento em campo, observação simples e levantamento junto a coordenação da Unidade, foi possível obter os dados necessários. Também foram consultados outros técnicos com larga experiência em MS e outros Estados.

Os coeficientes técnicos de preços e produtividade foram estimados pelos menores valores, objetivando expressar a realidade da agricultura familiar e as possíveis perdas.

A taxa de redução da produtividade de $25 \%$ para todas as culturas, durante o período avaliado, foi estipulada através de entrevista com produtores rurais e técnicos experientes, além de embasamento encontrado na literatura. A redução da produtividade foi prevista em $10 \%$ ao ano, no período em que o sombreamento afetará as frutíferas, enquanto que para a cultura cafeeira a redução será de $7 \%$ ao ano, a partir do $12^{\circ}$ ano.

Foram avaliados custos com mão de obra para marcação da área, coveamento, adubação, plantio e replantio, podas de manutenção, desbastes, controle fitossanitário, controle de gramíneas exóticas, aplicação de biofertilizantes, colheita, desfolha, desbrota, beneficiamento de produtos e sementes. O número de diárias estimado para o manejo do sombreamento, no período necessário, variou de 8 a 14 ha ano ${ }^{-1}$ entre os quatro arranjos agroflorestais, principalmente na cultura cafeeira.

Foi prevista aquisição de insumos orgânicos, sementes, maniva-mudas de mandioca, mudas de espécies arbóreas e adubação verde; além das despesas com subsolagem, gradeação, aração, limpeza da área e transporte de mudas e produção (valor hora-máquina $\mathrm{R} \$ 80,00$, em 2015).

As receitas são provenientes da produção de café, banana, mandioca de mesa, pimenta Cumari verdadeira, mamão, abacaxi, além das frutíferas para consumo in natura: lichia, aroeira pimenteira (pimenta-rosa) e jenipapo. Considerou-se que os produtos oriundos deste SAF são vendidos in natura para comerciantes e também na feira municipal.

Foram avaliados os seguintes indicadores de rentabilidade: valor presente líquido (VPL), taxa interna de retorno (TIR), relação benefício-custo (RB/C), tempo para recuperação do capital (payback simples e descontado), valor anual equivalente (VAE) e remuneração da mão de obra familiar (RMOF). Para análise da RMOF utilizou-se como referência o valor atual de mercado da diária no meio rural, $\mathrm{R} \$ 70,00$. Utilizou-se a taxa de juros ao ano de $2,5 \%$, que era o índice de financiamento do PRONAF Agroecologia (MDA, 2015). Foi estabelecido um horizonte de tempo de vinte anos para avaliação.

Foi realizada a leitura dos resultados a partir de um viés voltado para a sustentabilidade da agricultura familiar e para a restauração ecológica da área. Assim, contemplou-se receitas e despesas ajustadas, não-ajustadas e acumuladas, custos de implantação e demanda de mão de obra. 


\section{Resultados e Discussão}

Os arranjos agroflorestais analisados apresentaram grande diferença entre si no comportamento das receitas ao longo dos 20 anos analisados. Todos os arranjos de SAFs tiveram saldo negativo nos primeiros anos, sendo que os resultados positivos, financeiramente, só foram observados mais tarde, conforme observado no Fluxo de Caixa (Figura 2).

Figura 2 - Fluxo de caixa acumulado ajustado de arranjos agroflorestais implantados no Município de Ivinhema, MS, 2016: SAF 1 - Sistema café + banana; SAF 2 - Sistema café com floresta; SAF 3 - Sistema abacaxi; SAF 4 - Sistema cumari.

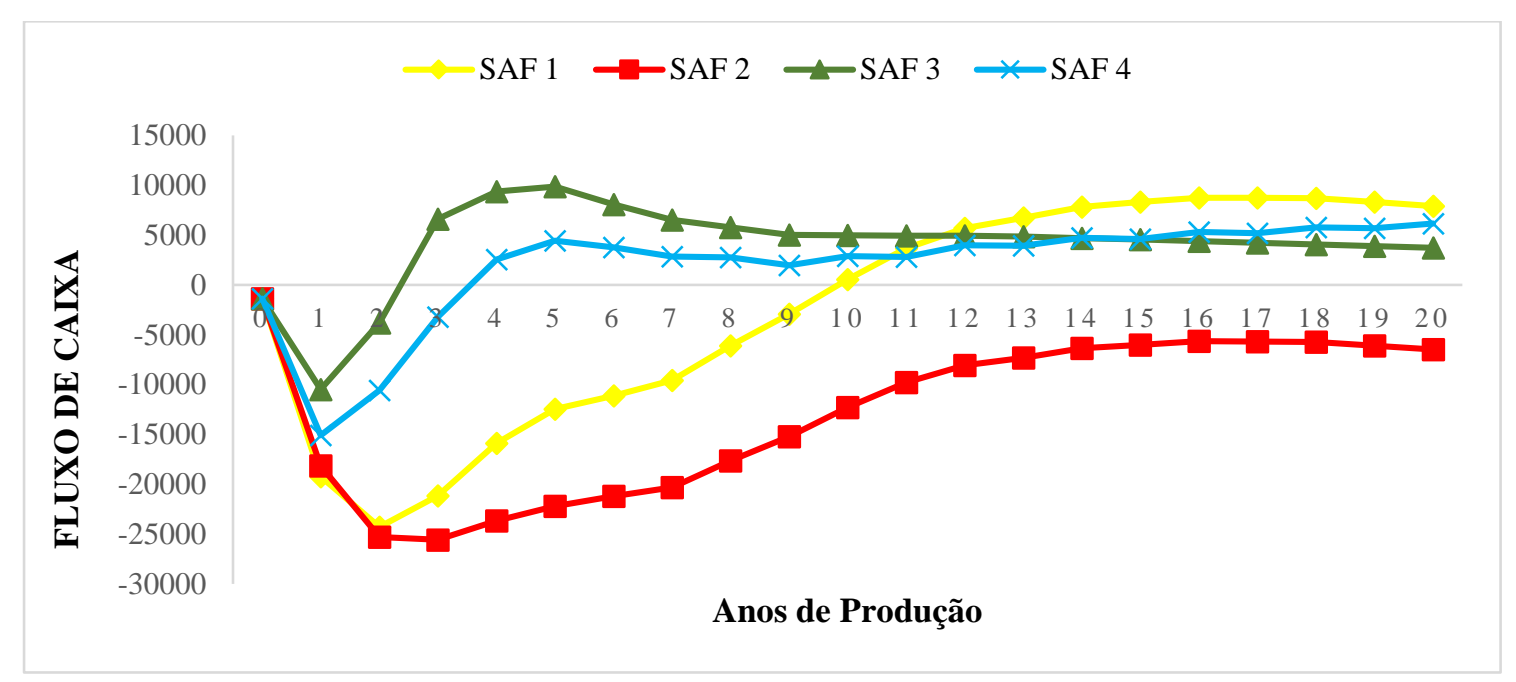

Fonte: Autores.

Observa-se que o Sistema Café + Banana foi mais produtivo entre o $3^{\circ}$ e o $5^{\circ}$ anos e o mais caro na implantação. O Sistema Café + Floresta foi mais produtivo no $4^{\circ}$ ano e mais caro no $1^{\circ}$ ano; Sistema Abacaxi, mais produtivo nos três primeiros anos e manutenção elevada até o $5^{\circ}$ ano e o Sistema Cumari teve maior renda entre o $2^{\circ}$ e o $5^{\circ}$ anos e maiores saídas nos cinco primeiros anos.

Todos os arranjos mostraram que o fluxo de caixa acumulado ajustado é ascendente do $2^{\circ}$ ano em diante. Mas os SAFs 3 e 4 apresentam receitas decrescentes a partir do $5^{\circ}$ ano, devido à saída das culturas anuais, pelo sombreamento do sistema e à queda de produtividade das espécies frutíferas. Nos SAFs 1 e 2 há fluxo de caixa ascendente a partir do $3^{\circ}$ ano, mas com leve queda no $17^{\circ}$ ano, considerando que o café produz até o vigésimo ano.

Além da produção de grãos maiores, o cultivo de café sombreado reduz gastos, pois traz vantagens não contabilizadas financeiramente, tais como: diminuição de gramíneas exóticas; retenção de umidade com economia na irrigação; maior aporte de nutrientes, com diminuição de insumos; redução de perdas por eventos climáticos; e maior tolerância à infestação de nematóides. Por outro lado, para evitar doenças fúngicas, devido ao sombreamento, após o $10^{\circ}$ ano é viável o desbaste de espécies arbóreas (Lunz, 2006; Concenço et al., 2012; Mancuso et al., 2013; Neto et al., 2018; Machado et al., 2020).

O Sistema Abacaxi é rentável nos cinco primeiros anos, diminuindo a partir do $5^{\circ}$ ano, devido à saída da banana, pimenta e mandioca, além do mamão no $7^{\circ}$ ano, período em que as árvores maiores farão muita sombra nos estratos inferiores. Do $6^{\circ}$ ano em diante, as receitas não superarão as despesas, pois, neste período, as duas únicas fontes de renda serão aroeira pimenteira e jenipapo, havendo prejuízo até o $20^{\circ}$ ano. Mas o SAF 3 poderá ser viável até o final, diminuindo-se o adensamento de espécies arbóreas.

Observando o fluxo de caixa e o saldo do projeto depois de 20 anos, após a dedução das despesas (Tabela 3) constatase que o SAF 1 apresentará o melhor rendimento, para o qual projeta-se uma renda líquida total de $\mathrm{R} \$$ 7.917,62 (valor presente líquido - VPL). 
Tabela 3 - Resumo dos valores em $\mathrm{R} \$$ para receita, despesa e saldo final de arranjos de sistemas agroflorestais biodiversos no Município de Ivinhema, MS, em 2016.

\begin{tabular}{ccccc}
\hline \multirow{2}{*}{ Resumo do Projeto } & \multicolumn{3}{c}{ Valores (em R\$) Ajustado (período de 20 anos) } \\
\cline { 2 - 5 } & Café + banana & Café com floresta & Abacaxi & Cumari \\
\hline Receitas & $108.071,25$ & $82.574,66$ & $96.956,00$ & $89.763,40$ \\
Despesas & $100.153,63$ & $89.034,24$ & $93.221,17$ & $83.605,49$ \\
Saldo Final & $7.917,62$ & $-6.459,58$ & $3.734,83$ & $6.157,91$ \\
\hline
\end{tabular}

Fonte: Autores.

O SAF 1 obteve VPL bom, porém, ao longo dos anos, o fluxo de caixa não foi vantajoso. O SAF 2 apresentou tênue inviabilidade financeira, pois não recuperará todo o valor investido. No entanto, considera-se que seria um SAF que amenizaria os custos de recuperação de área de reserva legal.

Embora o fluxo de caixa simples seja positivo no $4^{\circ}$ ano, será necessária intervenção a partir do $5^{\circ}$ ano. O desempenho insatisfatório se deve, primeiramente, ao espaçamento entre linhas ser de 2,5 metros. Mesmo com a poda das arbóreas, o sombreamento inviabilizará a produção das bananeiras a partir do $6^{\circ}$ ano.

O SAF 2 possui deficiência de planejamento devido ao alto custo de implantação $-1^{\circ}, 2^{\circ}$ e $3^{\circ}$ anos, sendo que, no $17^{\circ}$ ano, ele apresentou dificuldades de gerar receitas suficientes para minimizar os custos, pelo investimento inicial com arbóreas. Caso estivessem em menor número, o cenário seria positivo. A mão de obra não foi a causadora da inviabilidade, no entanto, $25 \%$ desta despesa se deu em decorrência da manutenção das arbóreas, que tiveram um custo de 20 mil reais, sem gerar receita. Por isso a reavaliação deve ser pautada na substituição delas por espécies que gerem renda.

O arranjo Café + Banana (SAF 1) demonstrou ser positivo, havendo geração de renda do $4^{\circ}$ ao $16^{\circ}$ ano, embora não satisfatória, pois o adensamento de espécies arbóreas (405 plantas espaçadas em três metros) demonstra uma vocação conservacionista para o SAF. Seria necessário, portanto, reduzir algumas espécies arbóreas e incluir outras com potencial de renda, como madeiráveis e frutíferas.

$\mathrm{Na}$ Tabela 4 são apresentados os principais indicadores financeiros para o período de 20 anos. Foram utilizados, como critérios financeiros para investimento em projetos, o valor anual equivalente (VAE) e o payback descontado, tendo por objetivo fornecer subsídio para decisões no contexto da agricultura familiar.

Tabela 4 - Indicadores financeiros para o período de 20 anos de implantação de arranjos agroflorestais em Ivinhema, MS, 2016.

\begin{tabular}{lcccc}
\hline \multicolumn{1}{c}{ Avaliação Financeira } & Café + Banana & $\begin{array}{c}\text { Café com } \\
\text { floresta }\end{array}$ & Abacaxi & Cumari \\
\hline TMA & $2,50 \%$ & $2,50 \%$ & $2,50 \%$ & $2,50 \%$ \\
TIR & $7,27 \%$ & $-1,39 \%$ & $39,39 \%$ & $14,11 \%$ \\
VPL & $7.917,62$ & $-6.459,58$ & $3.734,83$ & $6.157,91$ \\
Payback Simples & 10,0 & 31,0 & 3,0 & 4,0 \\
Payback Descontado & 10,0 & 31,0 & 3,0 & 4,0 \\
VAE & 507,89 & $-414,36$ & 239,58 & 395,01 \\
Relação B/C & 1,1 & 0,9 & 1,0 & 1,1 \\
\hline
\end{tabular}

Fonte: Autores. 
Conforme a Tabela 4, o VPL dos arranjos de SAFs 1 e 4 mostram-se positivos e viáveis financeiramente, de acordo com Lima Júnior (1995). Estes arranjos apresentam relação B/C maior ou igual a 1, portanto, os benefícios ultrapassam os custos, ou seja, as receitas são maiores que as despesas. Embora uma boa taxa interna de retorno (TIR) indique retorno, não deve ser analisada sem verificar inúmeros outros valores obtidos na análise. Por exemplo, o SAF 3 obteve indicadores positivos, o que não transmitiu a realidade, pois o VPL foi insatisfatório ao final de 20 anos.

Conforme Arco-Verde e Amaro (2010), quanto maior for o VAE, maior a viabilidade do projeto; portanto, o mais atrativo financeiramente é o Sistema Café + Banana, com Valor Anual Equivalente igual a R \$ 507,89. Como se vê na tabela 4, a relação benefício-custo é de 1,1 e a taxa interna de retorno é considerada normal para sistemas agroflorestais complexos.

Há, também, outros indicadores de grande relevância. No SAF 1, o payback foi projetado para o $10^{\circ}$ ano. Ou seja, no início de 2023, este sistema deverá começar a apresentar receitas maiores do que as despesas (Arco-Verde \& Amaro, 2014). Este tempo para recuperar o investimento pode ser considerado inviável para o pequeno produtor rural, caso tenha apenas esta atividade como fonte de renda. Mas essa é a realidade de SAFs com maior biodiversidade e presença de arbóreas sem fins comerciais, como o do presente estudo.

Entretanto, entre os quatro arranjos de SAFs, o Sistema Cumari (SAF4) gera as menores despesas ao longo do tempo, embora com elevado investimento inicial - $\mathrm{R} \$ 23.875,36$. O retorno do investimento estaria previsto para quatro anos, graças à receita gerada no primeiro ano, através da mandioca $(\mathrm{R} \$ 3.738,00)$ e da pimenta cumari ( $\mathrm{R} \$ 4.636,80)$. Comparativamente, $o$ SAF 1 gastou menos na implantação (R \$ 19.790,03) e obteve melhor saldo líquido, apesar de gerar lucro só a partir do $10^{\circ}$ ano.

Na relação benefício-custo, com desconto de 2,5\%, observa-se que, para cada $\mathrm{R} \$ 1,00$ investido, o retorno financeiro de cada arranjo será de: SAF $1(\mathrm{R} \$ 1,1)$; SAF $2(\mathrm{R} \$ 0,9)$; SAF $3(\mathrm{R} \$ 1,0)$ e SAF $4(1,1)$. Significa que dois tiveram pequeno retorno, o segundo representa prejuízo financeiro e o terceiro apenas neutraliza seus custos.

Para aprofundar a discussão é imprescindível analisar as despesas geradas pelos SAFs. Segundo Arco-Verde e Amaro (2014), a mão de obra é a despesa mais importante, cujo custo é consideravelmente alto nos primeiros anos (Figura 3).

Figura 3 - Gasto anual com diárias de mão de obra por hectare em arranjos de SAFs em Ivinhema, MS, 2016.

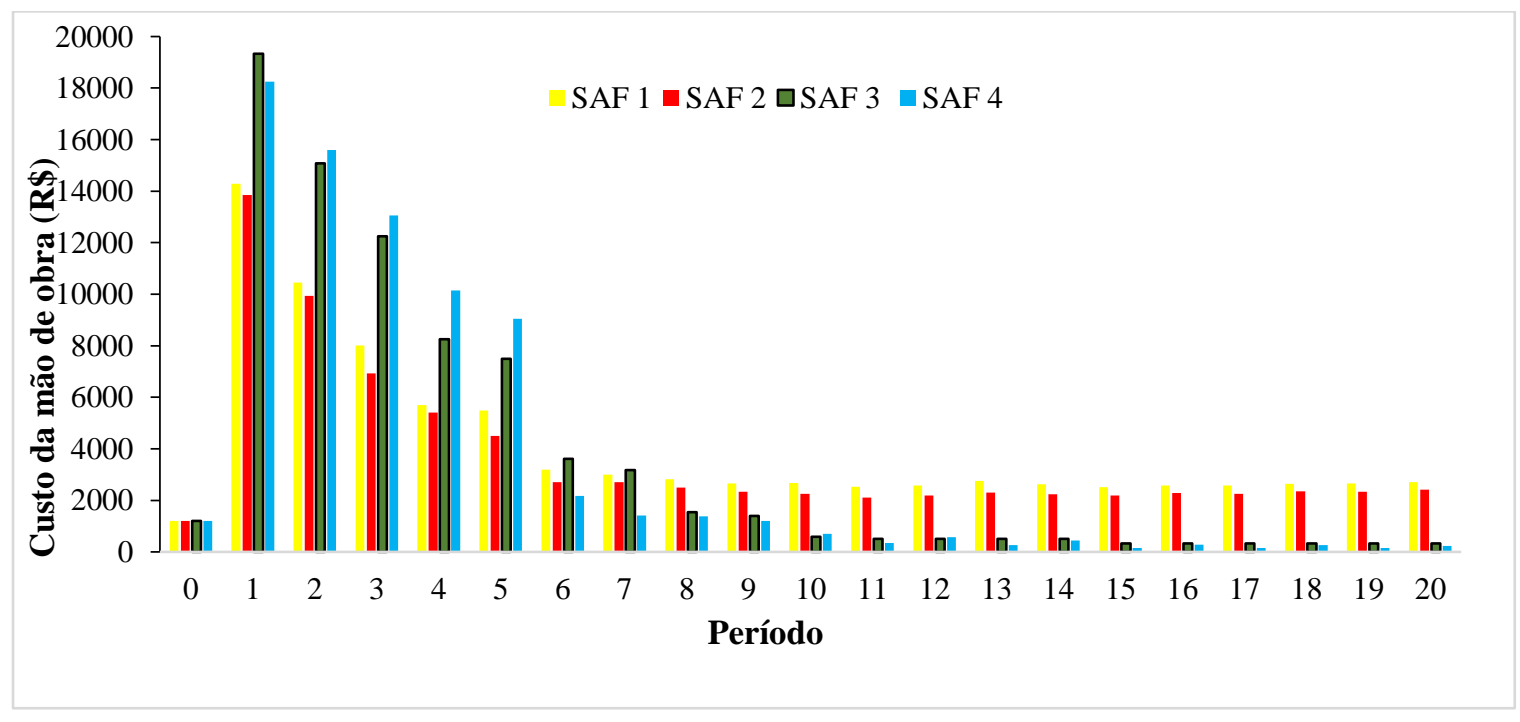

Fonte: Autores.

Os SAFs 1 e 2 demandaram menor contratação de mão de obra no período da implantação, mas têm gastos mais constantes na fase de estabilização (entre 30 e 40 diárias/ano/ha), que vai do $8^{\circ}$ ao $19^{\circ}$ anos (Arco-Verde et al., 2013). Os SAFs 
3 e 4 tiveram gastos elevados na fase de implantação (276 - 175 diárias/ano/ha), mas, após o $6^{\circ}$ ano, ficando somente as frutíferas produzindo nos sistemas, as despesas serão alocadas principalmente para a manutenção destas espécies. Neste período, as culturas anuais e semiperenes de ciclo curto são erradicadas, para permitir maior luminosidade ao sistema.

O sistema abacaxi estabiliza-se após o $15^{\circ}$ ano, com 4,6 diárias/ano/ha para o trato do jenipapo e eventuais roçadas. No sistema cumari há oscilações na demanda de mão de obra, devido à colheita da lichia - bianual: 2 diárias/ano/ha. O arranjo café + banana é o que apresenta maior gasto com mão de obra. Na figura 4 pode-se comparar o custo total com insumos e mão de obra para cada SAF, em de 20 anos:

Figura 4 - Despesas com mão de obra e insumos em diferentes arranjos de SAFs (em R\$) implantados no Município de Ivinhema, MS, 2016.

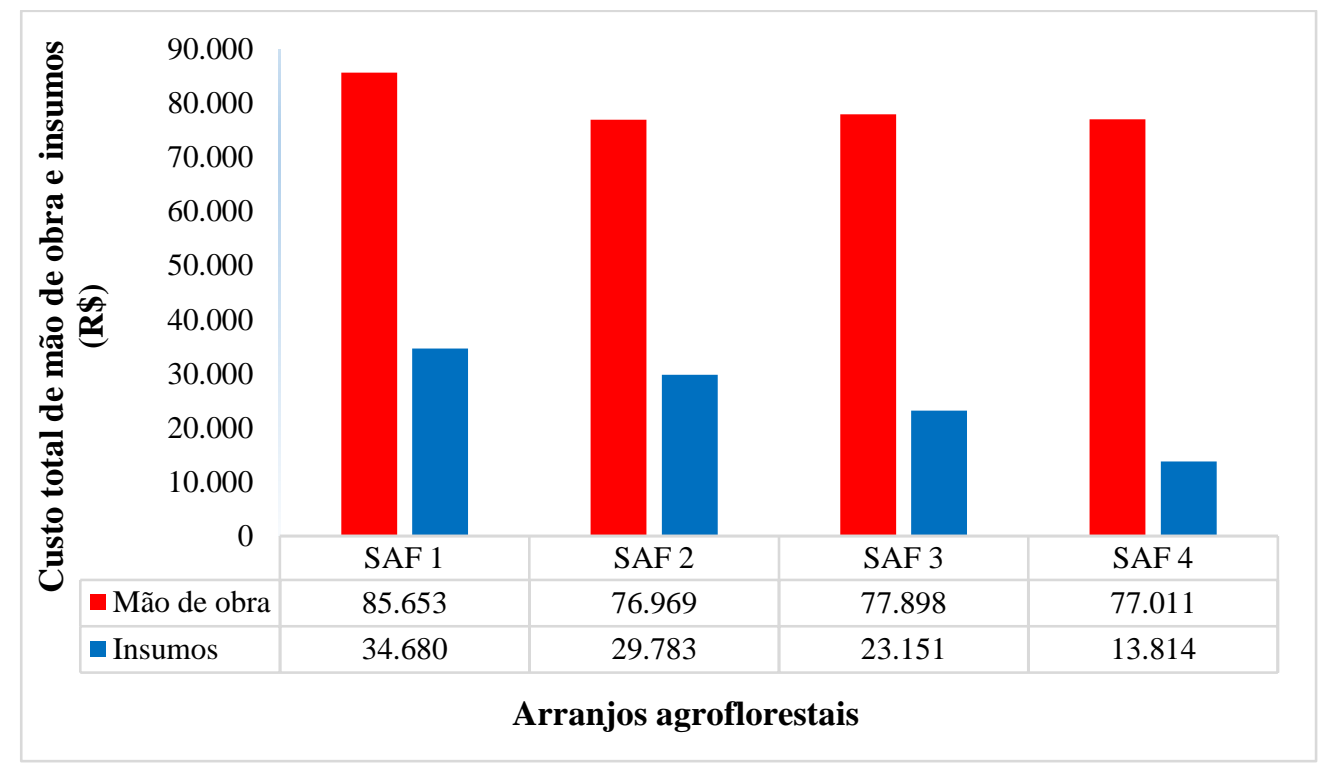

Fonte: Autores.

Devido à presença do café, o SAF 1 é o mais rentável, apesar de demandar maior quantidade de diárias/ha (mão de obra). O custo com mão de obra na implantação (preparo de solo e primeiro ano de cultivo) foi de $\mathrm{R} \$ 15.501,81$, mas diminuirá para $\mathrm{R} \$ 2.615 / \mathrm{ha} / \mathrm{ano}$, aproximadamente, do $11^{\circ}$ ao $20^{\circ}$ ano.

A despesa inicial com o preparo geral da área foi de $\mathrm{R} \$ 1.391,50$, em cada arranjo agroflorestal ( $\mathrm{R} \$ 184,00$ com insumos e $\mathrm{R} \$ 1.207,50$ com mão de obra e uso de máquinas agrícolas).

A implantação de todos os SAFs estudados, no primeiro ano do projeto, exigiu um investimento médio de $\mathrm{R} \$$ 22.077,00. O Sistema abacaxi foi o mais caro ( $\mathrm{R} \$ 30.203,00)$ : $\mathrm{R} \$ 7.152,09$ para plantio e manutenção de 712 plantas, e $\mathrm{R} \$ 10.092,89$ para implantar o abacaxi.

Como exposto na Figura 4, gasta-se mais com mão de obra do que com insumos, nos quatro arranjos. As despesas com diárias e máquinas correspondem, em média, a 76\% dos custos totais dos sistemas. De acordo com Arco-Verde e Amaro 2015, esta é a realidade de SAFs da agricultura familiar. Embora a mão de obra seja executada pela própria família, ela não deve ser ignorada nas análises financeira, pois representa o custo de oportunidade, conforme já citado por Palma et al. (2020) e Garcia et al. (2020).

Quanto aos gastos anuais com insumos (figura 5), nos quatro arranjos de SAFs, verifica-se que diminuem a partir do segundo ano. Os SAFs 1 e 2 mantêm essa despesa quase constante e responde por mais de 30\% da demanda total de insumos, com leves oscilações referentes ao combustível necessário para a comercialização da lichia, a cada dois anos. 
O SAF 3 demandou muito insumo durante a implantação, sendo 52,8\% dos gastos no cultivo do abacaxi. Neste arranjo e no SAF 4, os insumos tiveram queda significativa de gastos no sexto ano, devido à saída das culturas anuais e semiperenes, permanecendo somente as frutíferas, que demandam pouco insumo. No SAF 4, a pimenta gera as maiores despesas com insumos.

Figura 5 - Custo com insumos, durante 20 anos de produção, para diferentes arranjos agroflorestais em Ivinhema, MS, 2016.

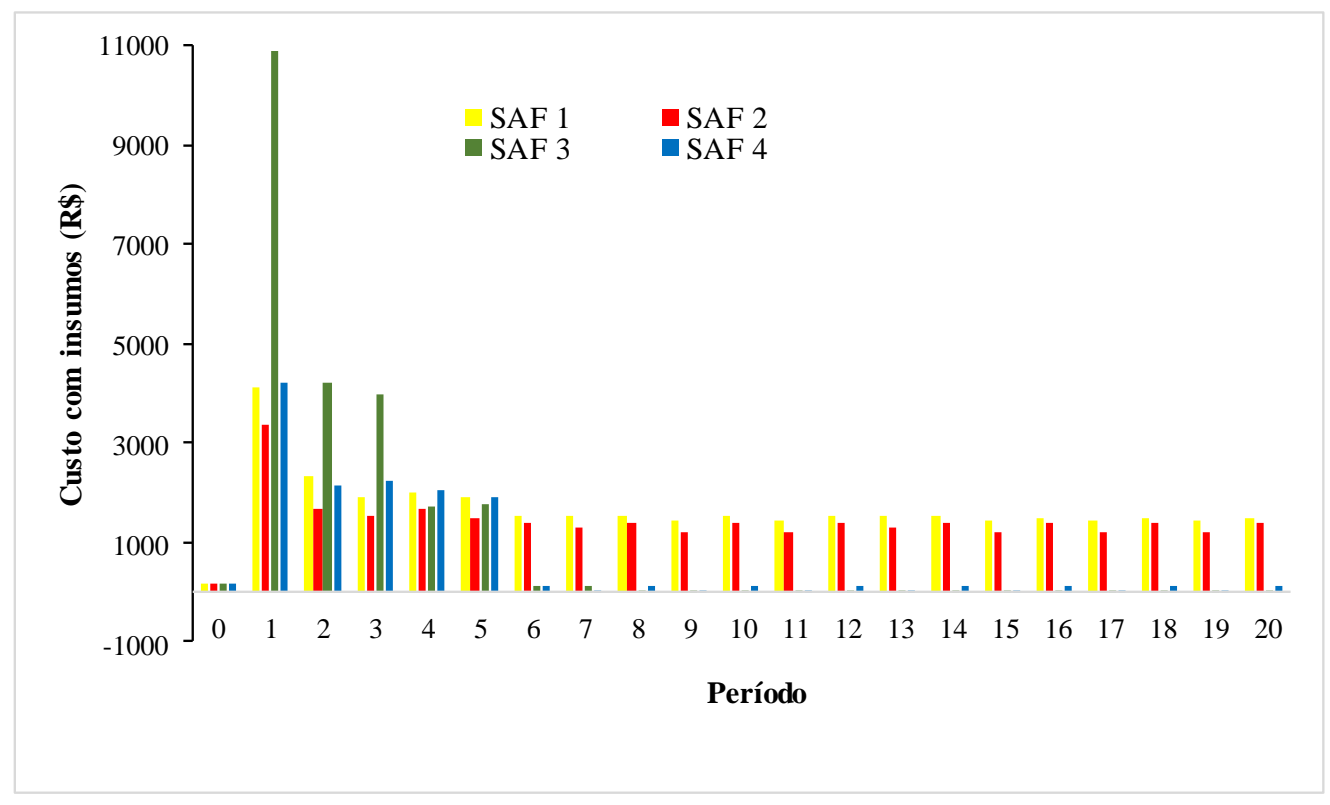

Fonte: Autores.

Observando a Figura 6, é possível avaliar quais seriam as culturas com melhor potencial para compor um SAF biodiverso e, consequentemente, proporcionar maior viabilidade financeira. Observa-se, nos quatro arranjos, que os cultivos apresentam receita superior aos custos, com exceção do mamão, no Sistema Abacaxi, e do jenipapo, em todos os sistemas. As espécies que mais contribuem com as receitas são: SAF 1 - café $(68,42 \%)$ e banana $(21,97 \%)$; SAF 2 - café $(75,86 \%)$ e banana $(15,89 \%)$; SAF 3 - mandioca $(30,24 \%)$ e abacaxi $(29,71 \%)$ nos três primeiros anos; SAF 4 - mamão $(39,14 \%)$ e pimenta $(17,58 \%)$, ambos nos cinco primeiros anos. 
Figura 6 - Custos e receitas por produto de arranjos agroflorestais em Ivinhema, MS, 2016.

SAF1

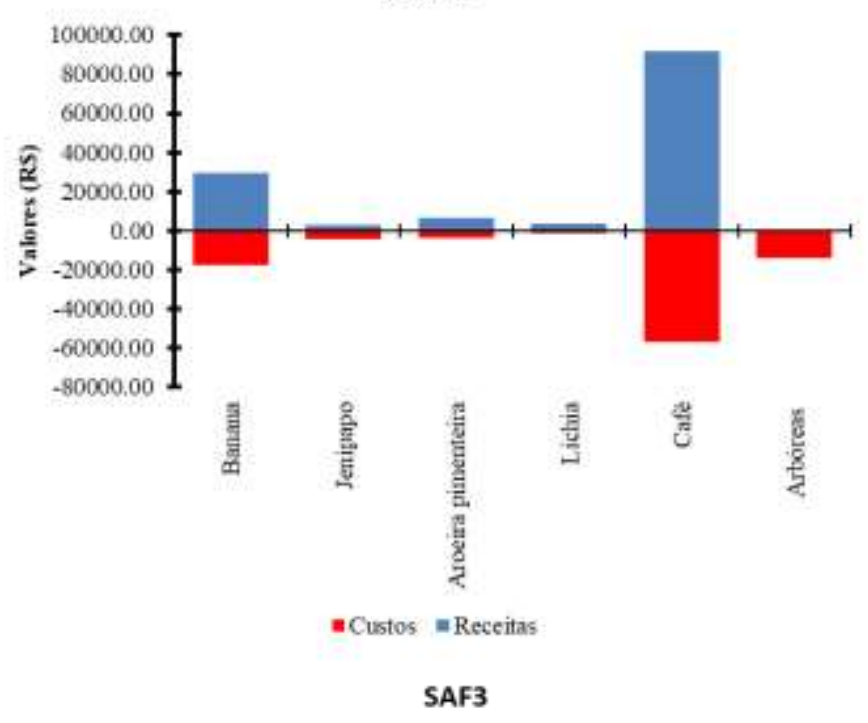

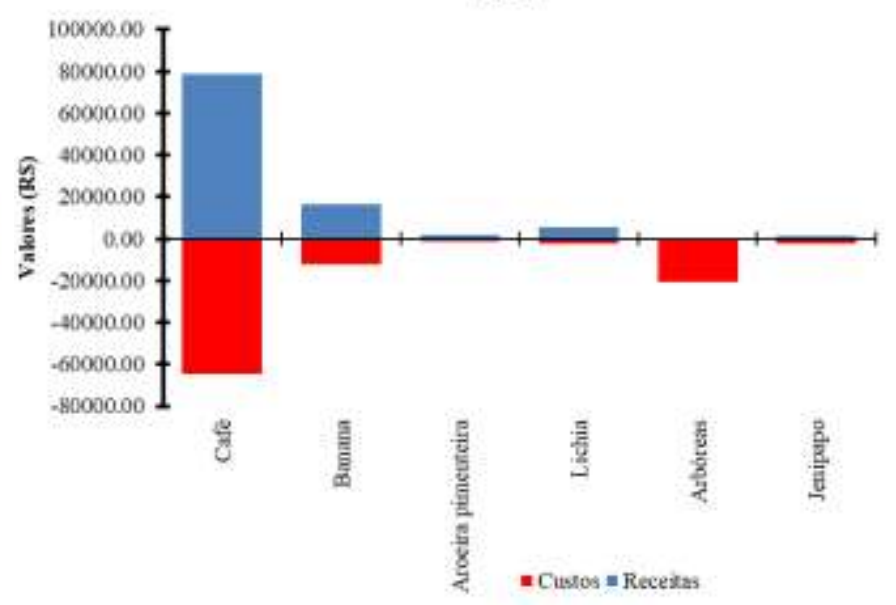

SAF4

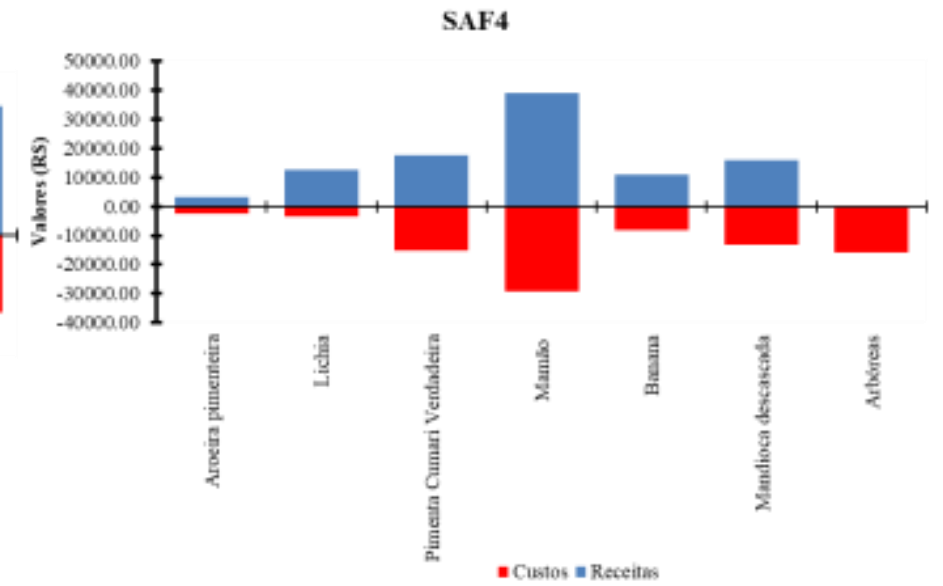

Fonte: Autores.

Para os SAFs 1 e 2, prevê-se que o máximo de produtividade da banana será no terceiro ano; enquanto o máximo do café será alcançado no $11^{\circ}$ ano, com 21 sacas/ano e 18 sacas/ano, respectivamente, enquanto sua média anual será de 14 (SAF 1) e 12 sacas (SAF 2), que corresponde à expectativa prevista nos modelos. É notável, nos arranjos de SAFs 1 e 2, a forte característica de "Agrofloresta de café", onde o foco é a conservação, enquanto a geração de renda vem em segundo lugar, buscando o retorno do investimento na recuperação da área.

Apesar do alto custo, o abacaxi (SAF 3) obtém um retorno positivo (R B/C 1,53), enquanto a pimenta cumari (SAFs 3 e 4) mostra um desempenho razoável (R B/C 1,1), aspecto relevante para a realidade do pequeno produtor rural.

A cultura do café destaca-se nessa análise financeira, demonstrando resultados promissores, ressalvadas algumas intervenções necessárias nos arranjos. A projeção de custos operacionais totais desta cultura será de $\mathrm{R} \$ 73.354,92$ para o SAF 1 (1.413 plantas ha $\left.{ }^{-1}\right)$, e de $\mathrm{R} \$ 64.767,97$ para o SAF 2 (1.215 plantas ha $\left.^{-1}\right)$.

Considerando todo período avaliado (20 anos), os SAFs 1, 2, 3 e 4 preveem remunerar a diária do agricultor familiar em $\mathrm{R} \$ 82,68 ; \mathrm{R} \$ 68,84 ; \mathrm{R} \$ 74,39$ e $\mathrm{R} \$ 79,32$, respectivamente. Sá et al. (2000) sugerem a RMOF como um indicador, para comparar a remuneração que o agricultor obteria com a venda de sua mão de obra (a diária local é de $\mathrm{R} \$ 70,00$ ) e a que obtém produzindo em sua própria área. Sendo assim, nos SAFs 1, 3 e 4, a RMOF apresenta, em média, uma relação de 12,55\% a mais 
no valor da diária atual paga em MS. Portanto, o produtor rural, além da vantagem de se fixar ao campo, tem ganho superior ao funcionário que vende sua força de trabalho na região.

Cabe destacar que, em alguns arranjos de SAFs estudados, a proporção da RMOF, em relação ao valor da mão de obra local, foi bem superior.

O arranjo café + banana é o de menor complexidade em relação aos outros três, e suas culturas têm, potencialmente, maior tempo de produtividade, devido à distância maior entre as linhas de arbóreas. Este se mostrou o mais rentável, porém é necessário intervir para diminuir o tempo de retorno do investimento.

O VAE deste Sistema (R \$ 507,89) também é mais vantajoso do que um sistema agrossilvipastoril em Mato Grosso do Sul, composto por soja, eucalipto e pecuária, cujo VAE foi de $\mathrm{R} \$ 451,47 \mathrm{ha}^{-1}$ (Silva, 2014).

Os custos de implantação mostram-se neutralizados em três dos arranjos estudados. Considerando-se estes como ferramenta para recuperar áreas degradadas ou recompor áreas de Reserva Legal, o objetivo seria atingido, havendo retorno do investimento, ficando evidente a vocação conservacionista desses SAFs biodiversos. Mantendo estes mesmos objetivos, seria possível gerar renda através de um espaçamento maior entre as fileiras de arbóreas e com a escolha adequada de espécies.

Os resultados obtidos na análise financeira evidenciam a relevância da escolha do arranjo e das espécies que comporão um sistema agroflorestal. No planejamento dos SAFs estudados privilegiou-se a questão ambiental. Assim, na perspectiva financeira, esses sistemas deveriam ter passado por intervenções, para que houvesse receita desde o primeiro ano, compensando o gasto na manutenção.

Baseando-se nas recomendações de Araujo et al. (2013), na hipótese de sombreamento excessivo, indica-se a poda ou supressão de espécies exóticas ou de $40 \%$ das espécies pioneiras, mas somente se estas representarem mais de $60 \%$ do total de espécies presentes.

No SAF 4 há necessidade de desbastar algumas espécies arbóreas, aumentar o espaçamento entre plantas ou substituílas por mais frutíferas que continuem produzindo em condições de sombreamento. Caso contrário, suspende-se a poda das arbóreas para evitar despesas e assume-se o papel preservacionista de Reserva Legal, a partir do $10^{\circ}$ ano.

Se for adotado o payback e o investimento inicial como critérios para a escolha do modelo mais viável, investindo menos, conclui-se que os componentes do SAF 4 (geram receitas mais imediatas) podem ser inseridos no arranjo do SAF 1, desde a fase de planejamento.

Em um sistema agroflorestal biodiverso, é possível associar componentes mais rentáveis, com um adequado espaçamento entre as arbóreas, para atender às demandas de geração de renda. No Sistema café + banana, pode-se inserir, nas entrelinhas, as culturas anuais de melhor custo-benefício do SAF4, procurando adiantar o payback.

Ao analisar os dados coletados, nos quatro modelos de SAFs implantados na perspectiva de recuperar áreas de Reserva Legal e promover a restauração dos serviços ambientais, deve-se considerar que qualquer retorno financeiro advindo da produção seja esperado.

\section{Conclusões}

Três dos arranjos agroflorestais analisados mostram-se viáveis financeiramente, pois apresentam VPL positivo, garantindo o retorno dos custos de implantação e manutenção. A principal despesa nos sistemas estudados é a mão de obra, sendo mais representativa no café.

O arranjo SAF 1 - Sistema café + banana - caracteriza-se como o de menor complexidade em relação aos outros três e suas culturas têm, potencialmente, maior tempo de produtividade, devido à distância maior entre as linhas de arbóreas. Este se concretizou como o mais rentável para o produtor rural, porém há necessidade de realizar intervenções para diminuir o tempo de retorno do investimento. 
Em todos os arranjos de SAFs estudados haverá sombreamento excessivo ao sistema, sendo, portanto, indicado realizar o desbaste de determinadas espécies arbóreas no $6^{\circ}$ ano e intensificar o plantio das culturas anuais e semiperenes, especialmente frutíferas.

\section{Agradecimentos}

Ao Curso de Pós-Graduação em Ciência e Tecnologia Ambiental da Universidade Federal da Grande Dourados. Ao CNPQ (Conselho Nacional de Desenvolvimento Científico e Tecnológico) pela bolsa de mestrado e pelo apoio financeiro processo $\mathrm{n}^{\circ} 427250 / 2016$.

\section{Referências}

Amaral-Silva, J., Schaffrath, V. R., Seoane, C. E., Arantes, A. C. V. \& Kaminski, T. C. G. (2015). Seleção de sistemas agroflorestais multiestrata para análise financeira. Cadernos de Agroecologia, 10(3), 1-5.

Arco-Verde, M. F. \& Amaro, G. C. (2010). Oficina sobre Sistemas Agroflorestais - Operação Arco Verde. Manaus: Embrapa Amazônia Ocidental.

Arco-Verde, M. F. \& Amaro, G. C. (2014). Análise financeira de sistemas produtivos integrados. Colombo/PR: Embrapa Florestas.

Arco-Verde, M. F.\& Amaro, G. C. (2015). Metodologia para análise da viabilidade financeira e valoração de serviços ambientais em sistemas agroflorestais. In: L. M. Parron, J. R. Garcia, E. B. de Oliveira, G. G. Brown, R. B. Prado (Orgs.). Serviços Ambientais em Sistemas Agrícolas e Florestais do Bioma Mata Atlântica. p.335-346. Brasília, DF: Embrapa. <https://www.alice.cnptia.embrapa.br/alice/bitstream/doc/1024363/1/MarceloAVLivroServicosAm bientaisCap30.pdf>.

Arco-Verde, M. F., Amaro, G. C. \& Silva, I. C. (2013). Sistemas agroflorestais: conciliando a conservação do ambiente e a geração de renda nas propriedades rurais. In: Anais... Congresso Brasileiro de Sistemas Agroflorestais, 9. Políticas públicas, educação e formação em Sistemas Agroflorestais na formação de paisagens sustentáveis. Manaus: SBSAF.

Balbino, L. C., Cordeiro, L. A. M., Porfirio-Da-Silva, V., Moraes, A., Martinez, G. B., Alvarenga, R. C., Kichel, A. N., Fontaneli, R. S, Santos, H. P., Franchini, J. C. \& Galerani, P. R. (2011). Evolução tecnológica e arranjos produtivos de sistemas de integração lavoura-pecuária-floresta no Brasil. Pesquisa Agropecuária Brasileira, 46(10), 1-12.

Camargo, G. M., Schlindwein, M. M., Padovan, M. P., \& da Silva, L. F. (2019). Sistemas Agroflorestais Biodiversos: Uma Alternativa Para Pequenas Propriedades Rurais. Revista Brasileira de Gestão e Desenvolvimento Regional, 15 (1), $34-46$.

Coelho, G. C. (2017). Ecosystem services in Brazilian's southern agroforestry systems. Tropical and Subtropical Agroecosystems, 20(3), 475-492.

Concenço, G., Motta, I. S., Correia, I. V. T., Silva, F. M. \& Salomão, G. B. (2012). Infestação de plantas espontâneas em cafeeiro solteiro ou consorciado em sistema agroecológico. Revista Agrarian, 6, 22-28.

Garcia, L. T., Paulus, L. A. R., Fernandes, S. S. L., Arco-Verde, M. F., Padovan, M. P. \& Pereira, Z. V. (2021). Financial viability of biodiverse agroforestry systems in the Brazilian Midwest. Research, Society and Development, 10(4), e47210413682. 10.33448/rsd-v10i4.13682. https://rsdjournal.org/index.php/rsd/article/view/13682. Acesso em: 3 jul. 2021.

IBGE. (2012). Manual técnico da vegetação brasileira. Série Manuais Técnicos em Geociências. 271p.

Jose, S. (2012). Agroforestry for conserving and enhancing biodiversity. Agroforestry Systems, 85(1), 1-8.

Köppen, W. \& Geiger, R. (1928). Klimate der Erde. Gotha: Verlag Justus Perthes.

Lima Júnior, V. B. (1995). Determinação na taxa de desconto para uso na avaliação de projetos de investimentos florestais. Dissertação. Universidade Federal de Viçosa.

Lunz, A. M. P. (2006). Crescimento e produtividade do cafeeiro sombreado a pleno sol. Tese (Doutorado em Agronomia). Universidade de São Paulo/ Escola Superior de Agricultura "Luiz de Queiroz". 
Machado, A. H. R., Puia, J. D., Menezes, K. C. \& Machado, W. (2020). A Cultura do Café (Coffea arabica) em Sistema Agroflorestal. Brazilian Journal of Animal and Environmental Research, 3(3), 1357-1369, doi: 10.34188/bjaerv3n3-053.

Mancuso, M. A. C., Soratto, R. P. \& Perdoná, M. J. (2013). Produção de café sombreado. Colloquium Agrariae, 9(1), 31-44.

MDA. (2015). Ministério do Desenvolvimento Agrário. Caderno PRONAF Agroecologia. Brasília. Disponível em: <http://www.mda.gov.br/sitemda/ sites/sitemda/files/ceazinepdf/Caderno_Pronaf_Agroecologia_Final.pdf> Accessed 05 jan 2016.

Miccolis, A., Peneireiro, F. M., Vieira, D. L. M., Marques, H. R. \& Hoffmann, M. R. M. (2019). Restoration through agroforestry: options for reconciling livelihoods with conservation in the Cerrado and Caatinga biomes in Brazil. Experimental Agriculture, 55 (S1), 208-225. 10.1017/S0014479717000138.

Neto, F. J. S., Morinigo, K. P. G., Guimarães, N. F., Gallo, A. S., Souza, M. D. B., Stolf, R. \& Fontanetti, A. (2018). Shade Trees Spatial Distribution and Its Effect on Grains and Beverage Quality of Shaded Coffee Trees. Journal of Food Quality, 18.

Padovan, M. P., Pereira, Z. V., Nascimento, J. S., Soares, J. A. B., Fernandes, S. S. L., Alves, J. \& Agostinho, P. (2019). Potencial de sistemas agroflorestais biodiversos em processos de restauração ambiental. In: T. de A. Rodrigues \& J. L. Neto. (Orgs.). Competência técnica e responsabilidade social e ambiental nas ciências agrárias. Ponta Grossa, PR: Atena Editora, 127-136.

Palma, V. H., Arco-Verde, M. F., Curcio, G. R., Galvão, F. \& Mattos, L. (2020). Análise financeira de sistema agroflorestal (SAF) orgânico do sul do Brasil. Enciclopédia biosfera, 17 (31), 26-39.

Sá, C. P., Santos, J. C., Lunz, A. M. P. \& Franke, I. L. (2000). Análise financeira e institucional dos três principais sistemas agroflorestais adotados pelos produtores do RECA. Circular técnica, 33. Embrapa Acre.

Silva, I. C. (2013). Sistemas Agroflorestais: conceitos e métodos. 1 ed. Itabuna: SBSAF.

Silva, I. M. (2014). A contribuição de sistemas de integração lavoura-pecuária-floresta para a sustentabilidade da produção agropecuária no Estado de Mato Grosso do Sul. Dissertação. Universidade Federal da Grande Dourados.

Silva, N. G. \& Silva, C. V. (2020). Percepção dos produtores rurais sobre os sistemas integrados na produção agropecuária (SIPAs). Brazilian Journal of Biosystems Engineering, 14(2), 172-186.

Souza, E. C. A. M. (2010). O estudo do regime pluviométrico na bacia hidrográfica do Rio Ivinhema e a construção de pluviogramas. Monografia. Universidade Federal da Grande Dourados.

Udawatta, R. P., Rankoth, L. M. \& Jose, S. (2019). Agroforestry and biodiversity. Sustainability, 11 (10), 2879. $10.3390 / \mathrm{su} 11102879$

Zomer, R. J., Neufeldt, H., Xu, J., Ahrends, A., Bossio, D., Trabucco, A. \& Wang, M. (2016). Global Tree Cover and Biomass Carbon on Agricultural Land: The contribution of agroforestry to global and national carbon budgets. Scientific reports, 6 (1), 1-12. 10.1038/srep29987 